\title{
Tribological behaviors of turbofan seal couples from friction heat perspective under high-speed rubbing condition
}

\author{
Siyang GAO, Weihai XUE, Deli DUAN, Shu LI* \\ Institute of Metal Research, Chinese Academy of Sciences, Shenyang 110016, China \\ Received: 14 January 2016 / Revised: 14 March 2016 / Accepted: 12 May 2016 \\ (C) The author(s) 2016. This article is published with open access at Springerlink.com
}

\begin{abstract}
The tribological behaviors of two types of seal coatings, nickel-graphite and aluminum-hexagon-boron nitride (Ni-Cg and Al-hBN, respectively) versus a Ti-6Al-4V blade used in turbofan engines were investigated using a high-speed rubbing test. The wear status and damage mechanism of the friction couples were studied and the abradability of the seal coatings was evaluated. By analysis of the coating properties and damage mechanism of the seal couple, the friction heat effect was identified as the key factor influencing blade wear forms as well as coating abradability. A one-dimensional heat conduction model was established to estimate the effect of increasing temperature on the friction interface. The results indicated that in the $\mathrm{Ni}-\mathrm{Cg}$ and $\mathrm{Ti}-6 \mathrm{Al}-4 \mathrm{~V}$ seal couple, the temperature rising rate (TRR) of the $\mathrm{Ti}-6 \mathrm{Al}-4 \mathrm{~V}$ blade was faster than that of the $\mathrm{Ni}-\mathrm{Cg}$ coating, and so the $\mathrm{Ti}-6 \mathrm{Al}-4 \mathrm{~V}$ blade softened earlier than the $\mathrm{Ni}-\mathrm{Cg}$ coating, causing the blade to suffer severe wear. In the Al-hBN and Ti-6Al-4V seal couple, the TRR of the Ti-6Al-4V blade was slower than that of the Al-hBN coating, and so the Al-hBN coating softened first; thus, blade damage was reduced or even replaced by coating adhesion. The square root ratio of thermal diffusivity between the blade and the coating could be taken as an indicator of the ratio of TRR between the blade and coating to predict blade wear status as well as damage mechanism. The results of the model agreed well with the experiment results of the two seal couples used in this study.
\end{abstract}

Keywords: seal coating; high-speed rubbing; wear mechanism; friction heat; thermophysical property

\section{Introduction}

In modern aircraft turbofan engines, the efficiency can be significantly improved and the fuel consumption markedly reduced by maintaining a small enough clearance between the rotating blade and the stationary casing. However, under very high speeds (higher than $100 \mathrm{~m} / \mathrm{s}$ ), reducing the clearance could cause a violent interaction between the blade tip and the casing surface because of thermal expansion, misalignment, and so on. The interaction could damage the blade, causing a reduction in efficiency; an even more serious problem is that the interaction may have disastrous consequences to the engine. Thermal sprayed seal coatings are a simple and weight-saving solution to

\footnotetext{
* Corresponding author: Shu LI.

E-mail: shuli@imr.ac.cn
}

this problem [1-4].

By powder spraying, the seal coating is applied to the inside casing wall of the engine, forming a special friction couple with the rotating blade, which is called a seal friction couple or seal couple. When the undesirable interaction between the coating and the blade occurs, the coating wears first, without damaging the blade tip, while maintaining an acceptable surface outline and roughness that is beneficial in terms of aerodynamics. Therefore, seal coatings must have good abradability [5].

Sprayed nickel- or aluminum-based seal coatings have been widely used in compressors of aircraft engines for many years. There is extensive literature concerning their tribological behaviors and wear status as a result of rubbing against titanium or superalloy blades. References [5-19] are representatives of the research. 
Nickel/graphite, one of the earliest developed nickel-based seal coatings, has been in service since the 1970s. The coating is mainly used in low-compressor rubbing against titanium blades. When the coating is well matched with the blade, the blade wear is slight.

Borel et al. [11, 12] investigated the damage mechanism of a nickel/graphite coating and a titanium blade seal couple. They found that cutting, smearing, adhesive transfer (blade to coating), and tribo-oxidation wear were the main wear mechanisms. They also pointed out that an increase in the coating temperature during rubbing was associated with the damage mechanism. Adhesive transfer wear induced a small increase in temperature, whereas cutting wear caused strong heating of the coating.

By analyzing changes in the mechanical properties of blades and coatings, Wang [13,14] found that when rubbed with a titanium blade, the yield stress of a nickel-based coating was higher than that of the titanium blade under high-speed rubbing conditions, and so the blade suffered severe wear.

In order to reduce the blade damage caused by nickel-based seal coatings, a series of aluminum-based seal coatings were developed, and extensive research on the tribological behavior and abradability of such coatings was carried out.

Bounazef et al. [15] studied the friction and wear behavior of an aluminum-based seal coating and a titanium alloy blade couple. The authors pointed out that blade damage was almost replaced by the adhesion of the coating material to the surface of the blade and that the adhesive level was mainly influenced by the incursion rate of the blade to the coating.

Ghasripoor et al. [16] investigated the damage mechanism of three types of aluminum-based seal coatings rubbed with a titanium alloy blade. They pointed out that, in most cases, blade damage was reduced by coating material adhesion. It was also found that, as compared to a conventional sliding friction couple, the solid lubrication in the seal friction couple reduced the plastic deformation of the coating in the surface region, enhancing wear debris formation and inhibiting adhesion of the coating materials to the blade.

Stringer and Fois acquired a macro-blade image during the rubbing process by using a stroboscopic imaging system [17-19]. They found that when the aluminum-based coating matched with the Ti-6Al-4V blade, both coating adhesion to blade and blade damage occurred simultaneously. The coating adhesion was enhanced under low incursion rates and the adhesive layer was peeled off by subsequent rubbing action.

In addition to experimental investigation, there have also been a few theoretical calculation studies that have focused on the temperature and rubbing energy of the rubbing interface.

By simplifying the question to a one-dimensional heat transfer problem and substituting the line rate of the coating material loss for the incursion rate, Bill established a thermal differential equation near the rubbing interface on the seal coating side [8]. The solution showed that the temperature of the coating had an inverse relationship with the incursion rate, which meant that a small incursion depth per bite would lead to a high coating temperature.

Laverty focused on the influence of test parameters on the rubbing energy and interface temperature of the seal coating [20]. The study showed that the rubbing energy was most significantly affected by the incursion rate, whereas sliding velocity and blade thickness were of secondary importance. Although the model Laverty used was mathematically very complicated, it was the first study that paid attention to the influence of the blade geometric profile. The most interesting result was the influence of the incursion rate on the coating temperature. Laverty's results showed that a large incursion rate would cause a higher coating temperature. The results are opposite those of Bill's. The reason was not clear yet.

Based on the interaction between the thermal effect and mechanical properties, an analytical model was established by Kennedy [21]. The results showed that the size of the contact hot patch was determined by the normal load and mechanical properties of the contacting materials. Among the results, the most important one was that the temperature at the contact hot patches can approach the melting point of the contacting materials. This finding demonstrated the importance of friction heat.

The above research brought our attention to the tribological behaviors of seal couples. However, one of the most important questions was why blade was damaged when coupled with nickel-based coatings, 
whereas it was "heightened" or "lengthened" when coupled with aluminum-based coatings. This has not been satisfactorily answered.

Furthermore, the theoretical calculation research paid too much attention to the influence of test parameters (such as incursion rate, sliding speed, and so on) on the temperature of the coating's rubbing interface, without taking into consideration the blade's temperature distribution. Also, material thermophysical properties, which have a directional effect and play a key role in heat conduction and transfer processes, have not been systematically studied.

In this study, the tribological behaviors of two types of seal coatings (Ni- or Al-based), which are widely used in turbofan engines, rubbing against Ti-6Al-4V blades at high speeds were investigated. The wear status and the damage mechanisms were studied and the abradability of the seal coatings was evaluated. A one-dimensional heat conduction model was established to estimate the increase in temperature at the friction interface for both the coating and the blade. The square root ratio of the thermal diffusivity of the blade and coating could be taken as an indicator of the ratio of temperature rising rate (TRR) between the blade and the coating to predict blade damage status.

\section{Experimental materials and method}

\subsection{Samples of coating and blade}

The seal coatings used in this study were nickel/ graphite $(\mathrm{Ni}-\mathrm{Cg})$ and aluminum/hexagon-boron nitride
(Al-hBN). Both seal coating samples were thermally sprayed onto a stainless steel plate. The $\mathrm{Ni}-\mathrm{Cg}$ coating was fabricated by flame spraying (FS) and the Al-hBN coating was fabricated by air plasma spraying (APS). The thicknesses of the coatings were approximately $1.5 \mathrm{~mm}$.

The cross-sectional morphologies of the two seal coatings are shown in Fig. 1. It is seen that both coatings consist of three phases: a metal skeleton phase (Ni or $\mathrm{Al})$, a solid lubrication phase ( $\mathrm{Cg}$ or $\mathrm{hBN})$, and a porous phase.

By calculating the area of the porous phase, the porosity (volume percentage) for both seal coatings was obtained. For the $\mathrm{Ni}-\mathrm{Cg}$ coating, the porosity was $25 \%-28 \%$ and for the Al-hBN coating, the porosity was $18 \%-23 \%$. To eliminate the effect of hardness, the hardness of the coatings used in this study was chosen as 45-50 HR15Y.

The blade was made of $\mathrm{Ti}-6 \mathrm{Al}-4 \mathrm{~V}$, an alloy that is widely used in aero-engine compressors. The blade's hardness and ultimate tensile strength (UTS) were 35 $\mathrm{HRC}$ and $928 \mathrm{MPa}$, respectively, at room temperature. The contact surface of the blade tip was a $4 \mathrm{~mm} \times$ $4 \mathrm{~mm}$ square. The sample was abraded and polished with sand paper to a surface roughness ( $\mathrm{Ra}$ ) of approximately $0.5 \mu \mathrm{m}$.

\subsection{Experimental method}

A home-made high-speed rubbing test rig was used to simulate the working conditions of the seal couple. Figure 2 shows a schematic and a photograph of the test rig. The rotor of the turbofan was replaced by a
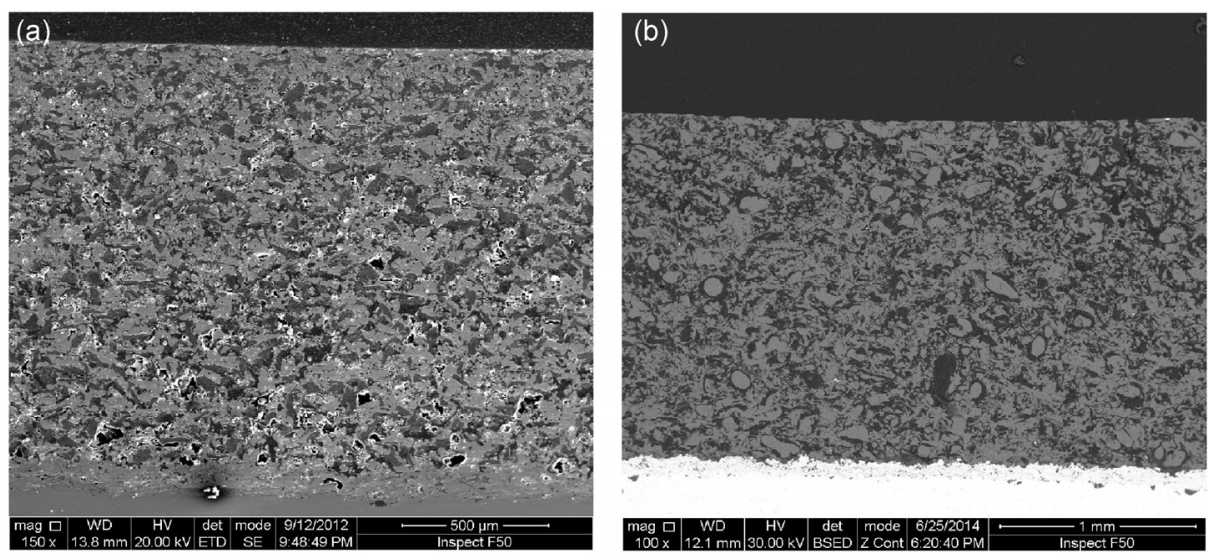

Fig. 1 Cross section of both seal coatings (a) Ni-Cg seal coating; (b) Al-hBN seal coating. 

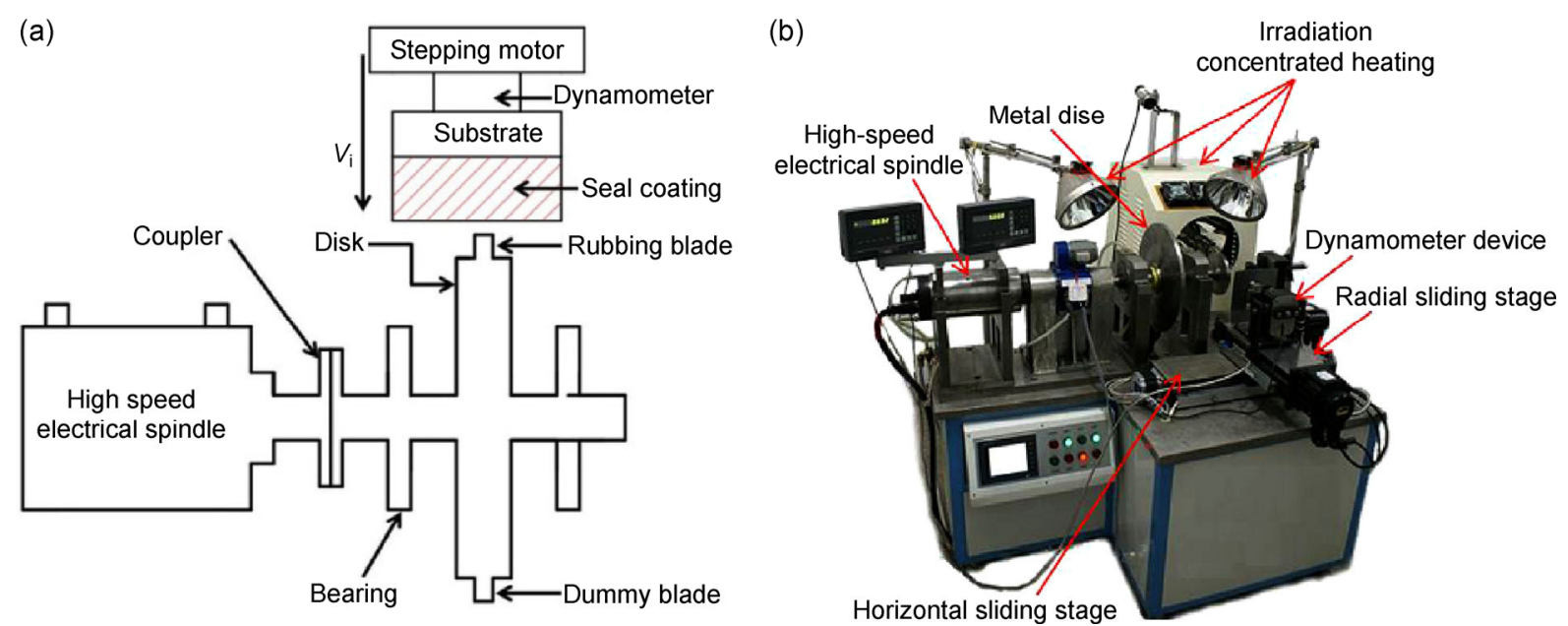

Fig. 2 The rig for the rubbing test: (a) schematic and (b) physical photograph.

rotary disc driven by a high-speed electrical spindle. The two blade samples were symmetrically fixed using a spacing of $180^{\circ}$ on the disc rim. It must be noted that only one blade sample could interact with the seal coating during the rubbing process; the other blade was shorter and was used to maintain the dynamic balance of the rotary disc. The rotational movement of the disc provided the linear velocity $\left(V_{\mathrm{t}}\right)$ of the blade, which varied from $30 \mathrm{~m} / \mathrm{s}$ to $150 \mathrm{~m} / \mathrm{s}$.

The coating sample was fastened onto a dynamometer and driven by a stepping motor. By adjusting the motor, the coating could move in a radial direction to the rotating blade at a given speed and a given displacement. The speed of coating radial moving to blade tip is defined as the incursion rate $\left(V_{\mathrm{i}}\right)$ and the displacement of the coating sample is defined as the incursion depth. For all the tests in this study, $V_{\mathrm{i}}$ was chosen as $20 \mu \mathrm{m} / \mathrm{s}$ and the incursion depth was chosen as $400 \mu \mathrm{m}$.

Changes to the weight and length of the blade samples after testing were determined by an electronic scale (with $0.1 \mathrm{mg}$ precision) and a micrometer (with $1 \mu \mathrm{m}$ precision), respectively. A positive value indicated weight loss or a decrease in the length of the blade. In contrast, a negative value indicated weight gain or increasing length.

The wear scar morphologies of the blade tip and coating were examined using an FEI INSPECT F50-type scanning electron microscopy (SEM) apparatus. The element distribution on the wear scar surface was studied with the equipped energy dispersive X-ray spectroscopy (EDS) apparatus.

\section{Experimental results and analysis}

\subsection{Wear status of the blade}

The length and weight changes (the average of at least three tests) of the blade samples versus the two types of seal coatings after rubbing tests at different linear velocities are shown in Fig. 3.

When rubbed against the $\mathrm{Ni}-\mathrm{Cg}$ coating, the Ti-6Al-4V blade tip suffered damage under all test conditions. The higher the linear velocity, the more severe the blade damage. At $V_{\mathrm{t}}=150 \mathrm{~m} / \mathrm{s}$, the length decreasing value is $221 \mu \mathrm{m}$. Considering that the given incursion depth was only $400 \mu \mathrm{m}$, this is equivalent to saying that when the $\mathrm{Ni}-\mathrm{Cg}$ coating was scratched by the blade tip incursion, the blade damage was $55 \%$ of the incursion depth, which indicates poor abradability for the $\mathrm{Ni}-\mathrm{Cg}$ coating under this condition.

For the blade rubbed against the Al-hBN coating, the situation was totally different. Under all test conditions, the length and weight changes of the blade were negative, meaning that the blade length and weight increased primarily because of the adhesion of the coating material onto the blade tip surface.

It is worth noting that for the Al-hBN couple, the increase in blade length was not proportional to the increase in blade weight at $V_{\mathrm{t}}=90 \mathrm{~m} / \mathrm{s}$. This anomalous phenomenon could be due to the coating adhesion to the blade tip and the blade damage taking place at the same time [18]. Other causes may include the difference in density between the coating and the blade, adhesive coating materials just covering parts 
of the blade surface, peeling of the adhesion layer from the blade tip, and so on.

\subsection{Damage mechanism}

\subsubsection{Ni-Cg and Ti-6Al-4V couple}

Figure 4 shows the wear scar morphologies of the $\mathrm{Ni}-\mathrm{Cg}$ coating after rubbing tests at different linear

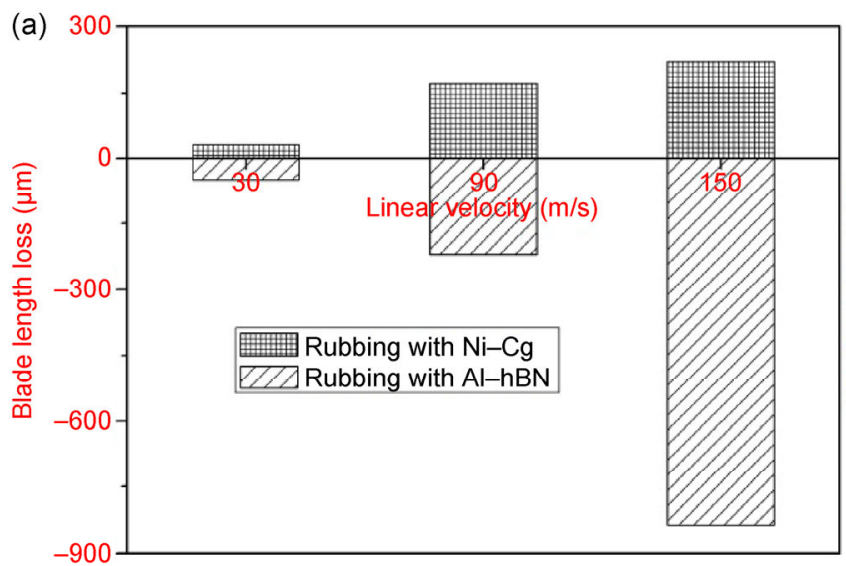

Fig. 3 Blade length and weight changes after rubbing test under different linear velocity: (a) length change value and (b) weight change value.

velocities.

Under low linear velocity $(30 \mathrm{~m} / \mathrm{s})$, the main damage mechanisms of the coating were smearing and cutting. Smearing caused crashing of the coating, resulting in a relatively smooth scar surface (area A in Fig. 4(a)), whereas cutting caused the coating materials to peel off, leaving a roughened the surface (area B in Fig. 4(a)).

At higher linear velocities, instead of smearing and

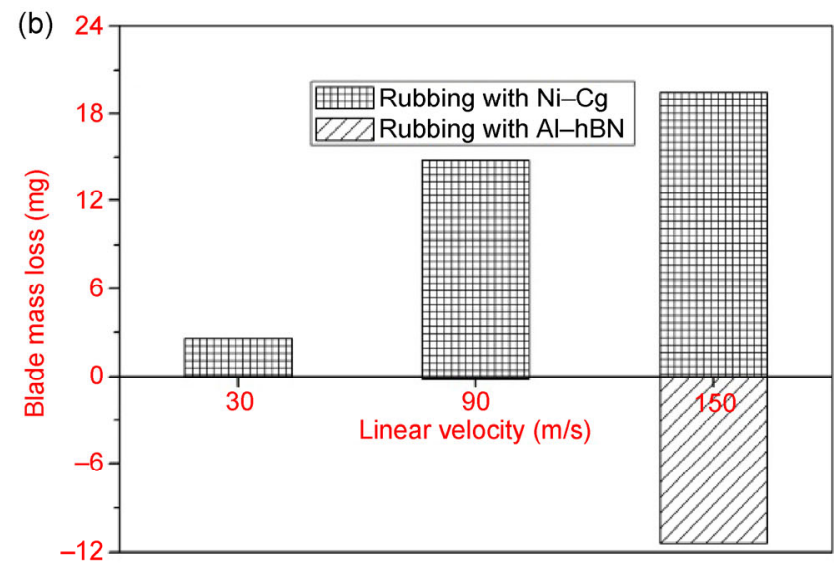

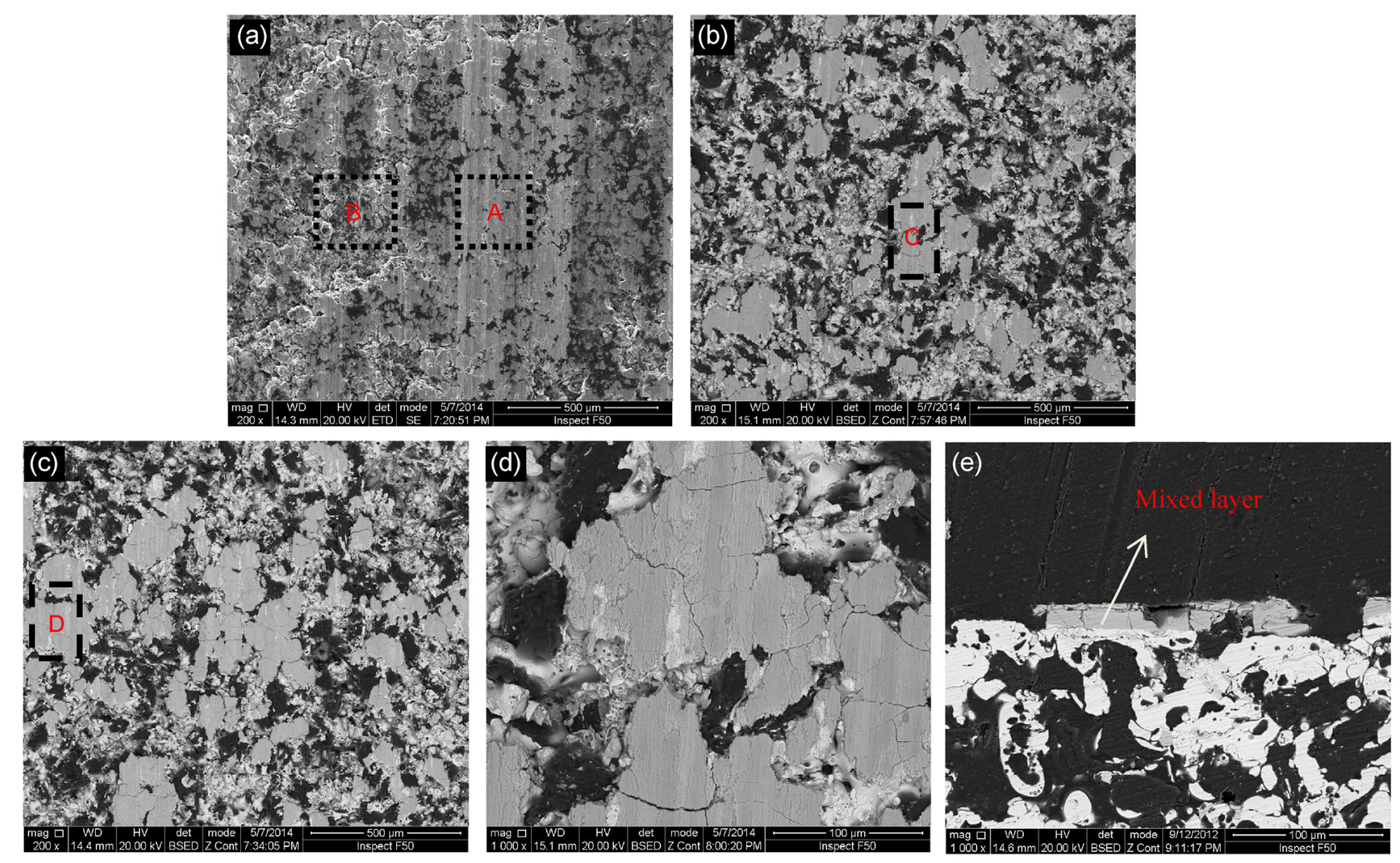

Fig. 4 Wear scar morphologies of Ni-Cg coating after rubbing test under different linear velocity (SEM): (a) $V_{\mathrm{t}}=30 \mathrm{~m} / \mathrm{s},(\mathrm{b}) V_{\mathrm{t}}=90 \mathrm{~m} / \mathrm{s}$, (c) $V_{\mathrm{t}}=150 \mathrm{~m} / \mathrm{s}$, (d) amplification of a block in Fig. 4(c), and (e) cross section of the mixed layer. 
cutting, there were many blocks on the wear scars of the coatings (Figs. 4(b) and 4(c)). Table 1 presents the EDS results of blocks from area C in Fig. 4(b) and area D in Fig. 4(c). The blocks were mainly composed of $\mathrm{Ti}$ and $\mathrm{Al}$ from the blade and $\mathrm{Ni}$ and $\mathrm{C}$ from the coating, as well as large amounts of $\mathrm{O}$. With increasing linear velocity, the content of $\mathrm{O}$ increased and those of $\mathrm{Ni}$ and $\mathrm{Cg}$ decreased.

Combined with the fierce-spark phenomenon that appeared at high linear velocities during the rubbing tests, it could be concluded that the transferred $\mathrm{Ti}$ and $\mathrm{Al}$ from the blade with $\mathrm{Ni}$ in coating as well as $\mathrm{O}$ formed a mixed layer as the block covering on the wear scar of the coating. The main components of the mixed blade-coating layer were $\mathrm{Ti}, \mathrm{Ni}, \mathrm{Al}$, and their oxides.

Figures $4(\mathrm{~d})$ and $4(\mathrm{e})$ show a higher magnification image and the cross section of the blade-coating mixed layer, respectively. There are many network cracks on the surface of the block; cracks can also be observed throughout the mixed layers. Considering repeated interaction during rubbing between the blade and coating, it seems plausible that crack initiation and propagation must take place. If the cracks intersected, the mixed layer may peel off, which would promote the transfer of materials from the blade to the coating, thus exacerbating blade damage.

Table 2 presents the micro-hardness values of the metal phase of the original coating and the mixed layer. The mixed layer hardness was approximately three times higher than that of the metal phase. The results seem to confirm the main components of the

$\underline{\text { Table } 1 \text { EDS results of area C in Fig. 4(b) and area D in Fig. 4(c). }}$

\begin{tabular}{ccccccc}
\hline \multirow{2}{*}{ Region } & \multicolumn{6}{c}{ Element (wt\%) } \\
\cline { 2 - 7 } & $\mathrm{C}$ & $\mathrm{O}$ & $\mathrm{Al}$ & $\mathrm{Ti}$ & $\mathrm{V}$ & $\mathrm{Ni}$ \\
\hline Area C in Fig. 4(b) & 13.63 & 34.72 & 5.57 & 34.42 & - & 11.66 \\
Area D in Fig. 4(c) & 6.24 & 47.33 & 5.24 & 35.73 & 0.59 & 4.89 \\
\hline
\end{tabular}

Table 2 Microhardness of metal phase and mixed layer on the wear scar of $\mathrm{Ni}-\mathrm{Cg}$ coating.

\begin{tabular}{ccc}
\hline $\begin{array}{c}\text { Test condition of } \\
\text { samples }\end{array}$ & Position & $\begin{array}{c}\text { Microhardness } \\
(\mathrm{MPa})\end{array}$ \\
\hline Original coating & Metal phase & 381.7 \\
$90 \mathrm{~m} / \mathrm{s}$ tested & Mixed layer & 1039.6 \\
$150 \mathrm{~m} / \mathrm{s}$ tested & Mixed layer & 918.5 \\
\hline
\end{tabular}

mixed layer and the inability of these mixed layer blocks to reduce the wear of the blade tip.

Figure 5 shows the wear surface morphologies of the Ti-6Al-4V blade tip after rubbing tests at different linear velocities. Under a slow linear velocity $(30 \mathrm{~m} / \mathrm{s})$, there were many small grooves on the rubbing surface of the blade tip (Fig. 5(a)), which means the blade tip suffered abrasive wear. There were also some lightgray blocks diffused on the surface (Fig. 5(b)). The EDS results showed that the major element of these blocks was $\mathrm{Ni}$, which was transferred from the coating to the blade tip.

When the linear velocity reached $90 \mathrm{~m} / \mathrm{s}$ (Fig. 5(c)), the light-gray blocks almost disappeared. It was decided that the blade tip exhibited abrasive wear and plastic deformation, and thus blade wear loss sharply increased at $90 \mathrm{~m} / \mathrm{s}$ (see Fig. 3).

At $150 \mathrm{~m} / \mathrm{s}$, friction oxidation near the flow trail appeared, as shown by the black area in Fig. 5(d). The appearance of plastic deformation and friction oxidation means that fierce frictional heat was generated, causing serious softening during high-speed rubbing.

Figure 6 shows the cross-sectional morphologies of the blade tip after rubbing tests under different linear velocities. It is clearly seen that the profile of the blade tip changes from smooth to bumpy, which means that the degree of material loss and plastic deformation of the blade surface increased from mild to severe with increasing linear velocity.

\subsubsection{Al-hBN and Ti-6Al-4V couple}

Figures 7 and 8 show the surface and the cross section, respectively, of the Ti-6Al-4V blade tip, and Fig. 9 shows the wear scar morphologies of the Al-hBN coating after rubbing tests under different linear velocities. It is clearly seen that linear velocity has a very important effect on the adhesive behavior of the coating material onto the blade.

Under a low linear velocity $(30 \mathrm{~m} / \mathrm{s})$, coating adhesion to the blade was slight. Most areas of the blade tip surface were bare, and the thickness of the adhesion layer was very small and thin (Figs. 7(a) and 8(a)). The main damage mechanism was micro-cutting of the coating (Fig. 9(a)). The friction surface of both the blade tip and the coating was relatively smooth.

When the linear velocity increased to $90 \mathrm{~m} / \mathrm{s}$, coating 

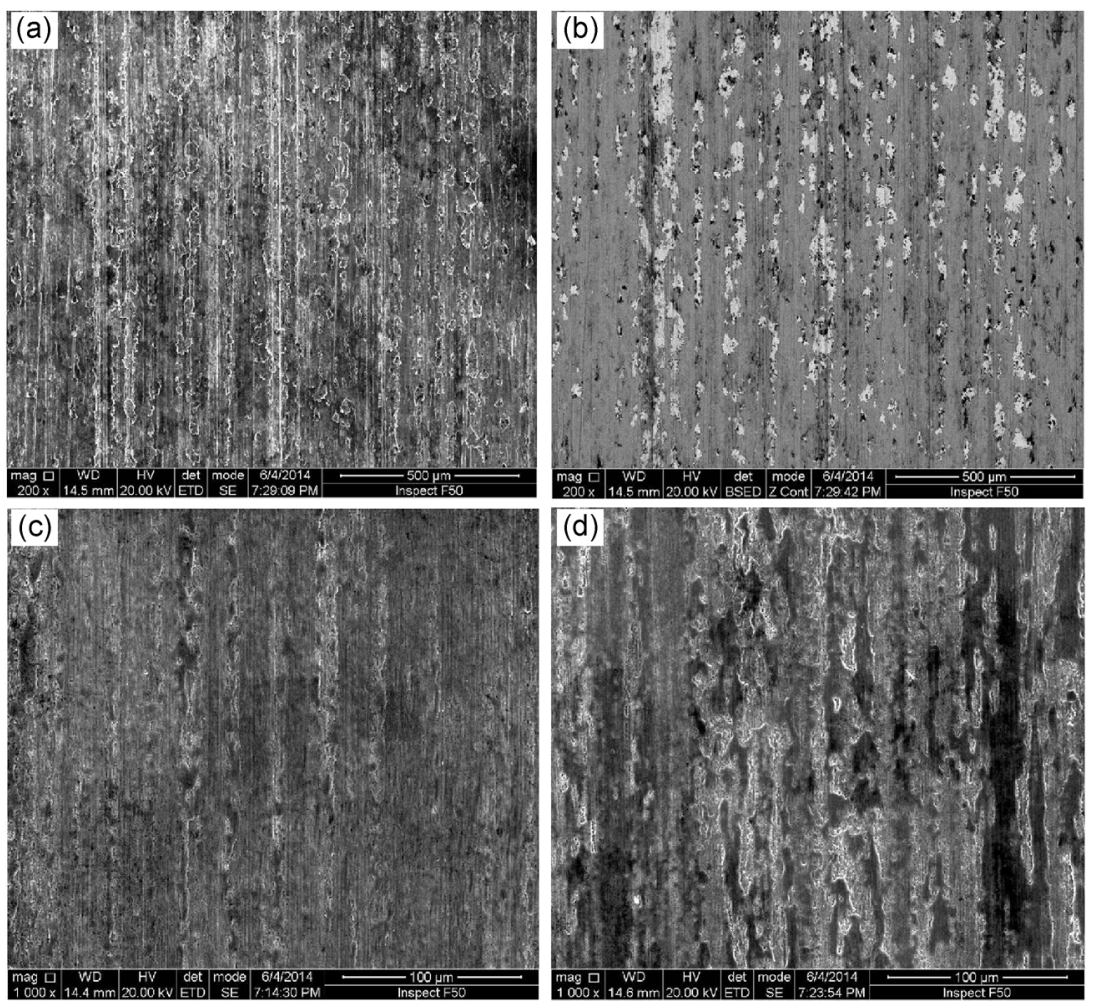

Fig. 5 Wear surface morphologies of blade tip after rubbing test under different linear velocity (SEM): (a) $30 \mathrm{~m} / \mathrm{s}$, (b) $30 \mathrm{~m} / \mathrm{s}$, (c) 90 $\mathrm{m} / \mathrm{s}$, and (d) $150 \mathrm{~m} / \mathrm{s}$.
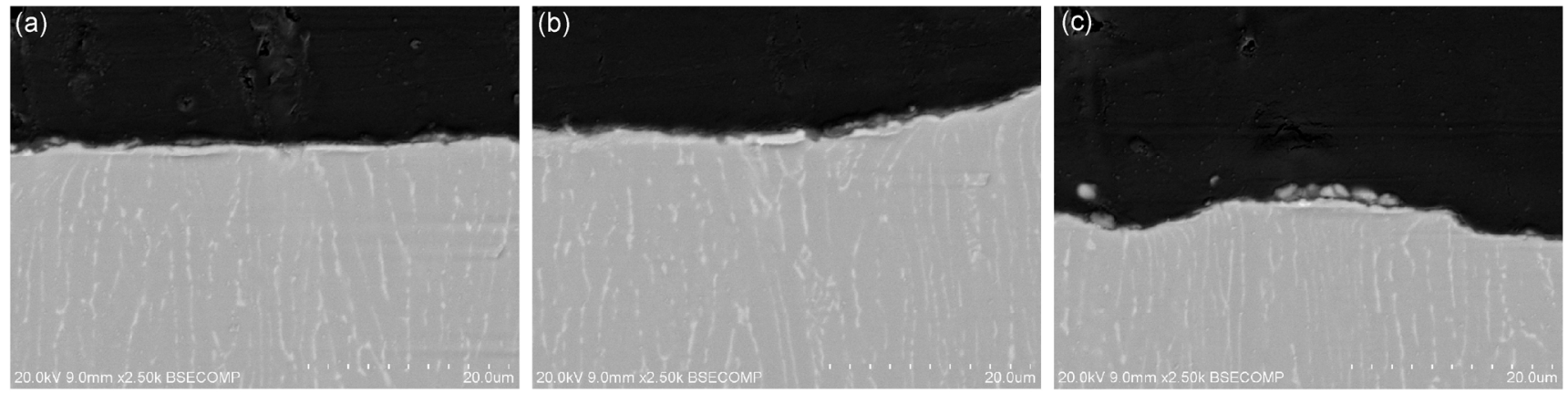

Fig. 6 Cross section morphologies of blade tip after rubbing test under different linear velocity (SEM): (a) $30 \mathrm{~m} / \mathrm{s}$, (b) $90 \mathrm{~m} / \mathrm{s}$, and (c) $150 \mathrm{~m} / \mathrm{s}$.
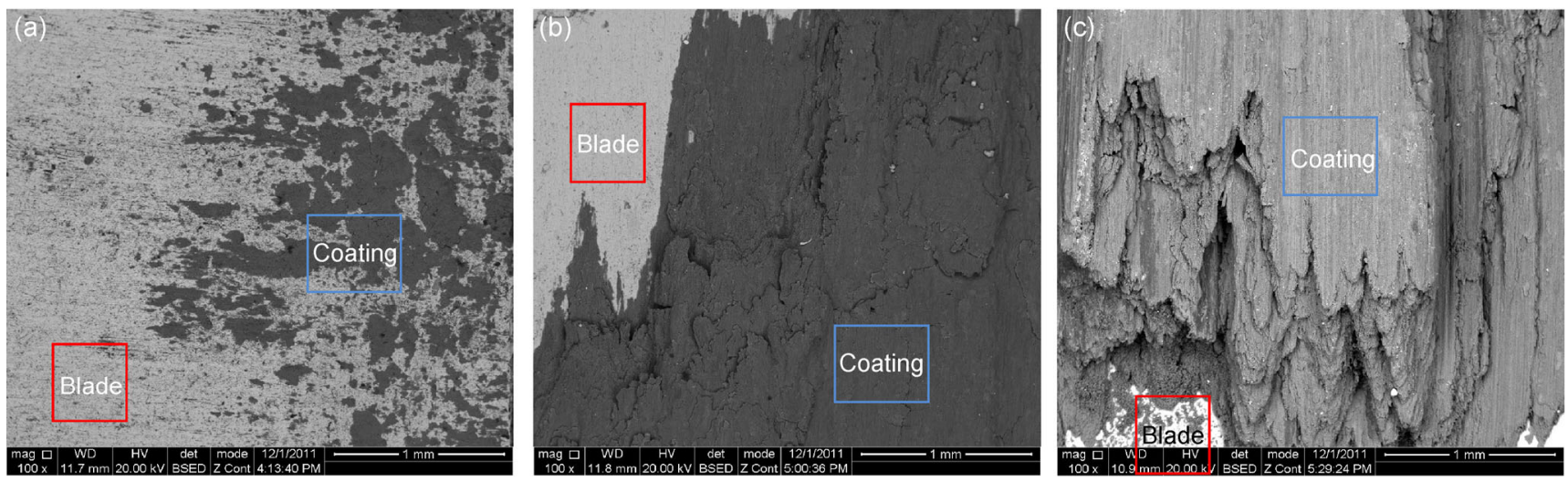

Fig. 7 Surface of blade tip after rubbing test under different linear velocity (SEM): (a) $30 \mathrm{~m} / \mathrm{s}$, (b) $90 \mathrm{~m} / \mathrm{s}$, and (c) $150 \mathrm{~m} / \mathrm{s}$. 

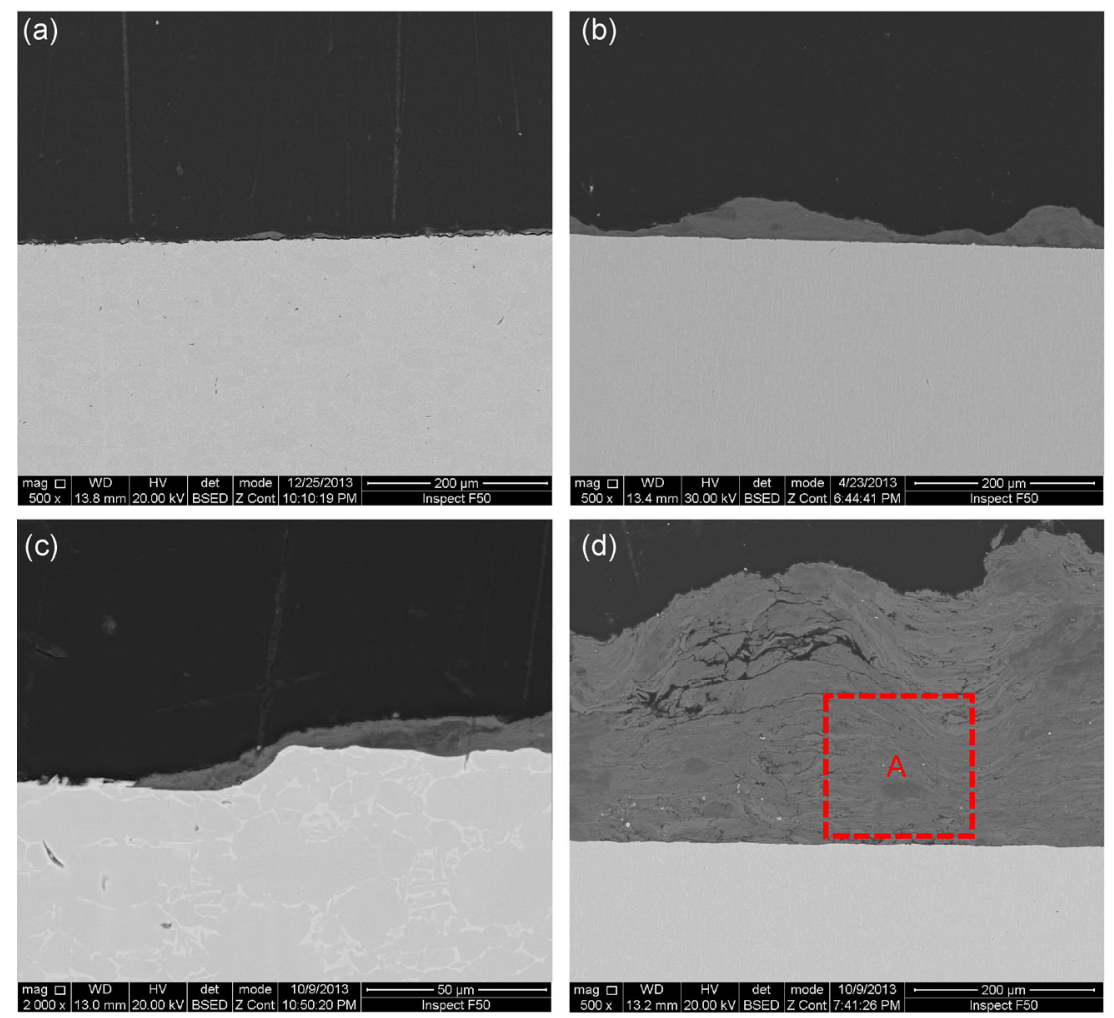

Fig. 8 Cross section of blade tip after rubbing test under different linear velocity (SEM), (a) $30 \mathrm{~m} / \mathrm{s}$, (b) 90 m/s, (c) 90 m/s, and (d) 150 m/s.
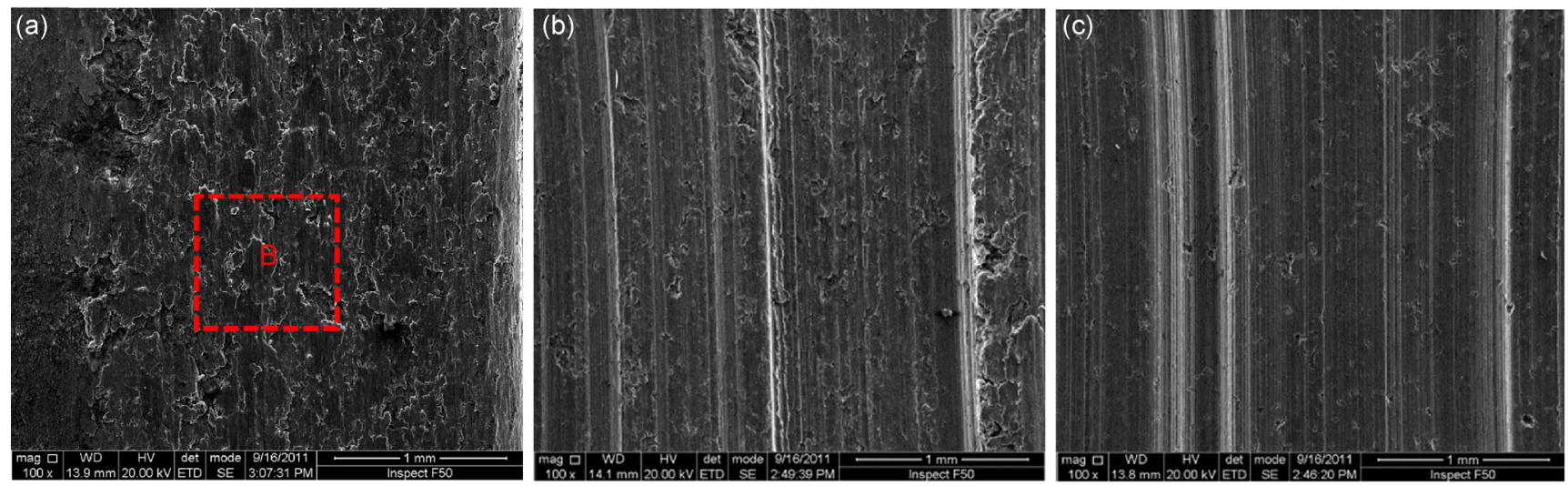

Fig. 9 Wear scar morphologies of Al-hBN coating after rubbing test under different linear velocity (SEM): (a) $30 \mathrm{~m} / \mathrm{s}$, (b) $90 \mathrm{~m} / \mathrm{s}$, and (c) $150 \mathrm{~m} / \mathrm{s}$.

adhesion to the blade was enhanced. Most areas of the blade tip surface were covered by the coating material, forming a wavy adhesive layer with a certain thickness (Figs. 7(b), 8(b), and 8(c)). It could be concluded that the interaction between the blade and the coating turned into an interaction between the adhesive layer and the coating. This caused a ploughed appearance on the coating surface (Fig. 9(b)). Abrasive/ploughing wear thus became the main damage mechanism of the coating.

As the linear velocity reached $150 \mathrm{~m} / \mathrm{s}$, coating adhesion was strongly enhanced. Nearly all of the blade tip surface was covered by the coating material, which had an obvious layered structure (Fig. 7(c)). The thick adhesive layer was lumpy, and there were much larger ploughing grooves on the coating surface (Figs. 8(d) and 9(c)). The main damage mechanism of the coating still was abrasive/ploughing wear. 
Table 3 presents the EDS results of area A in Fig. 8(d) and area B in Fig. 9(a). The adhesive layer on the blade tip was mainly composed of $\mathrm{Al}$ from the coating. Also, there were no elements from the blade on the surface of the coating wear scar. The above analysis results correspond well with the wear status in that the blade damage was very slight when the Ti-6Al-4V blade was rubbed against the Al-hBN coating.

It must be pointed out that although the blade rubbed against the Al-hBN coating had little wear because of the adhesion of the coating materials onto the blade tip, there are still at least three disadvantages to the coating in terms of abradability.

First, coating material adhesion onto the blade tip caused lengthening of the blade, which may alter the running state and dynamic balance of the rotor, interfering with the safe operation of the turbofan engine.

Second, the lengthened blade increased the incursion depth into the seal coating, which reduced the coating service life.

Third, as shown in Figs. 9(b) and 9(c), the adhesive layer on the blade tip resulted in many large grooves on the coating surface, making the coating surface very rough, which is bad for aerodynamics.

According to the above reasons, the Al-hBN coating did not show good abradability under high-speed rubbing conditions.

Table 3 EDS results of area A in Fig. 8(d) and area B in Fig. 9(a).

\begin{tabular}{cccccc}
\hline \multirow{2}{*}{ Region } & \multicolumn{5}{c}{ Element (wt\%) } \\
\cline { 2 - 6 } & $\mathrm{N}$ & $\mathrm{O}$ & $\mathrm{Al}$ & $\mathrm{Si}$ & $\mathrm{Ni}$ \\
\hline Area A in Fig. 8(d) & 10.95 & 13.58 & 73.53 & 1.94 & - \\
Area D in Fig. 9(a) & 13.38 & 12.07 & 69.99 & 4.56 & - \\
\hline
\end{tabular}

\section{Discussion}

\subsection{Setup of one-dimensional heat conduction model}

As a sacrificed material, seal coatings are designed to match with the blade and protect it from friction damage or lengthening as much as possible. However, because the service conditions of seal friction couples are harsh and the coating also requires erosion resistance and so on, so far none of the seal coatings could fully meet the abradability requirement and solve the clearance sealing problem in turbofan engines.
As a special tribological behavior, abradability is strongly influenced by the working conditions and properties of the friction couple materials. The two types of seal coatings used in this study had similar hardness values (45-50 HR15Y), and yet the specific energy consumption (SEC) of the Al-hBN coating was higher than that of the Ni-Cg coating $\left(0.7 \mathrm{~J} / \mathrm{mm}^{3}\right.$ versus $0.4 \mathrm{~J} / \mathrm{mm}^{3}$ ) as measured by the single-pass pendulum impact scratching test [22]. Meanwhile, the elastic modulus and UTS of aluminum-based coatings are also higher than those of nickel-based coatings $[23,24]$. Thus, it seems logical that as compared to the Al-hBN coating, the Ni-Cg coating, which has poor mechanical properties, should be the better candidate to protect the $\mathrm{Ti}-6 \mathrm{Al}-4 \mathrm{~V}$ blade from damage under the same working conditions.

However, the experimental results showed the opposite case, in that the $\mathrm{Ni}-\mathrm{Cg}$ coating seriously damaged the blade and even caused blade material transfer to the coating. The results for the Al-hBN coating were different in that not only was there no damage, but also the blade was lengthened by coating adhesion. In addition, a strong spark phenomenon appeared in the $\mathrm{Ni}-\mathrm{Cg}$ and $\mathrm{Ti}-6 \mathrm{Al}-4 \mathrm{~V}$ couple, yet there was nearly no spark phenomenon in the Al-hBN and $\mathrm{Ti}-6 \mathrm{Al}-4 \mathrm{~V}$ couple during the high-speed rubbing process.

Based on the above facts, it could be said that friction heat and thermophysical properties may play an important role in the tribological behaviors of seal couples during the high-speed rubbing process, and much more attention should be paid to these properties rather than to just the mechanical properties when evaluating the abradability of a seal coating.

Therefore, a heat conduction model was established to estimate the temperature situations on the friction interface for both the coating and the blade. For convenience, some assumptions were made as follows: $>$ During the rubbing process, neither the coating nor the blade exhibited any phase changes and there was no internal heat source. Also, the effect of other possible chemical reactions to the friction heat was neglected.

$>$ As compared to the incursion depth direction, the temperature variation along the scratch width and thickness direction was very small. The problem was thus considered a half-infinite plate problem, 
and the heat conduction was assumed to have occurred only in the depth direction. Also, the temperature distribution, $T$, near the friction interface is just the function of the depth coordinate $x$ and the interaction time $t$, i.e., $T=T(x, t)$.

$>$ The frictional force during one rubbing process was a constant value.

$>$ The thermophysical properties for both the coating and the blade remained constant with increasing temperature.

$>$ Friction heat was transferred only to the blade and coating from the interface; no heat was exchanged between the blade and the coating.

The transfer of heat from the friction interface to the coating and the blade is shown in Fig. 10. According to energy conservation and Fourier's law, the heat diffusion equation near the friction interface on the coating side can be written as

$$
\frac{\partial T_{c}}{\partial t}=a_{c} \cdot \frac{\partial^{2} T_{c}}{\partial x^{2}}, x>0
$$

with the boundary condition

$$
\left\{\begin{array}{l}
t=0, T(x, t)=T_{\mathrm{c} 0} \\
t>0,-\left.K_{\mathrm{c}} \cdot \frac{\partial T(0, t)}{\partial x}\right|_{x=0}=q_{\mathrm{c}}
\end{array}\right.
$$

where $a_{c}$ is the coating's thermal diffusivity, $K_{\mathrm{c}}$ is the coating's thermal conductivity, $q_{\mathrm{c}}$ is the heat flux flowing into the coating from the friction interface, and $T_{\mathrm{c} 0}$ is the coating's initial temperature in one rubbing process.

The solution for Eq. (1) [25] is the temperature distribution with $x$ and $t$ in the coating.

$$
\begin{aligned}
T_{\mathrm{c}}\left(x, t_{\mathrm{p}}\right)-T_{\mathrm{c} 0}= & \frac{2 \cdot q_{\mathrm{c}} \cdot \sqrt{\frac{a_{\mathrm{c}} \cdot t_{\mathrm{p}}}{\pi}}}{K_{\mathrm{c}}} \cdot \exp \left(\frac{-x^{2}}{4 \cdot a_{\mathrm{c}} \cdot t_{\mathrm{p}}}\right) \\
& -\frac{q_{\mathrm{c}} \cdot x}{K_{\mathrm{c}}} \cdot \operatorname{erfc}\left(\frac{x}{2 \sqrt{a_{\mathrm{c}} \cdot t_{\mathrm{cp}}}}\right), \quad x>0
\end{aligned}
$$

where $\operatorname{erfc}(x)$ is the Gaussian complementary error function and $t_{\mathrm{cp}}$ is the time duration of one rubbing process for the coating.

Correspondingly, the temperature distribution of

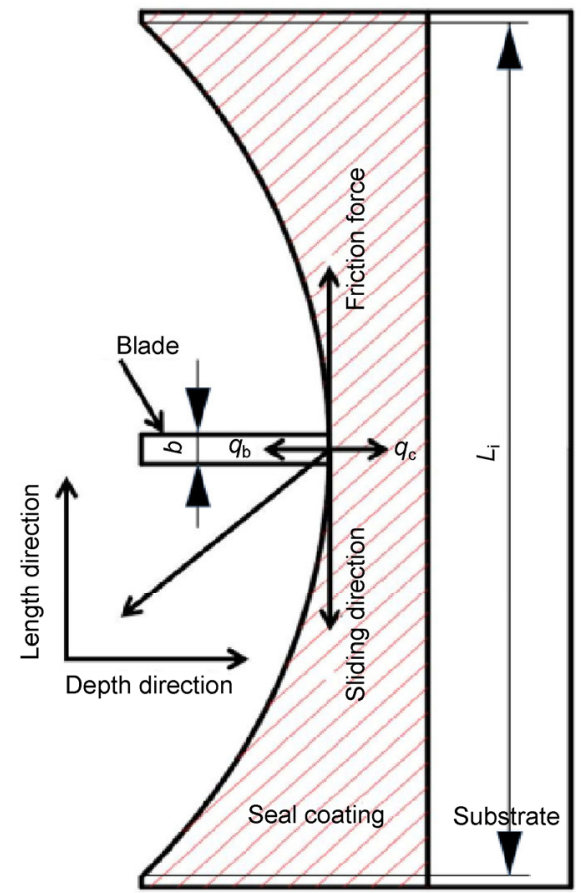

Fig. 10 Schematic diagram of heat flow model during rubbing process.

the blade near the friction interface can be written as

$$
\begin{aligned}
T_{\mathrm{b}}\left(x, t_{\mathrm{p}}\right)-T_{\mathrm{b} 0}= & \frac{2 \cdot q_{\mathrm{b}} \cdot \sqrt{\frac{a_{\mathrm{b}} \cdot t_{\mathrm{p}}}{\pi}}}{K_{\mathrm{b}}} \cdot \exp \left(\frac{-x^{2}}{4 \cdot a_{\mathrm{b}} \cdot t_{\mathrm{p}}}\right) \\
& +\frac{q_{\mathrm{b}} \cdot x}{K_{\mathrm{b}}} \cdot \operatorname{erfc}\left(\frac{-x}{2 \sqrt{a_{\mathrm{b}} \cdot t_{\mathrm{bp}}}}\right), \quad x<0
\end{aligned}
$$

where $a_{\mathrm{b}}$ is the blade's thermal diffusivity, $K_{\mathrm{b}}$ is the blade's thermal conductivity, $q_{\mathrm{b}}$ is the heat flux flowing into the blade from the friction interface, $T_{\mathrm{b} 0}$ is the blade's initial temperature in one rubbing process, and $t_{\mathrm{bp}}$ is the time duration of one rubbing process for the blade.

At the friction interface where $x \rightarrow 0$, Eqs. (3) and (4) can be written as follows:

$$
\begin{aligned}
& T_{\mathrm{c}}\left(x, t_{\mathrm{cp}}\right)-T_{\mathrm{c} 0}=\lim _{x \rightarrow 0^{+}}(\text {Eq.(3) })=\frac{2 \cdot q_{\mathrm{c}} \cdot \sqrt{\frac{a_{\mathrm{c}} \cdot t_{\mathrm{cp}}}{\pi}}}{K_{\mathrm{c}}} \\
& T_{\mathrm{b}}\left(x, t_{\mathrm{bp}}\right)-T_{\mathrm{b} 0}=\lim _{x \rightarrow 0^{-}}(\text {Eq. }(4))=\frac{2 \cdot q_{\mathrm{b}} \cdot \sqrt{\frac{a_{\mathrm{b}} \cdot t_{\mathrm{bp}}}{\pi}}}{K_{\mathrm{b}}}
\end{aligned}
$$


Equations (5) and (6) give the temperature increase at the friction interface during one rubbing process for the coating and blade, respectively. The value can also be perceived as the temperature change as a function of rubbing time, and so it is termed as the temperature rising rate, i.e., TRR, in this paper.

Assuming that all the friction translates into heat during the rubbing process, then the total heat flux $q$ can be written as follows:

$$
q=\frac{F_{\mathrm{t}} \cdot L}{(L \cdot a) \cdot\left(L / V_{\mathrm{t}}\right)}
$$

where $F_{\mathrm{t}}$ is the friction force, $L$ is the scratching length, $V_{\mathrm{t}}$ is the blade linear velocity, and $a$ is the scratching width, which also equals the width of the blade tip (Fig. 11).

In a seal friction couple, both the blade and the coating share a part of the total heat flux $q$ during the rubbing process. The higher the thermal conductivity, the larger the sharing of heat flux $q$. Therefore, the relationship between $q_{\mathrm{b}}$ and $q_{\mathrm{c}}$ can be written as follows:

$$
\left\{\begin{array}{l}
q_{\mathrm{b}}+q_{\mathrm{c}}=q \\
\frac{q_{\mathrm{b}}}{q_{\mathrm{c}}}=\frac{K_{\mathrm{b}}}{K_{\mathrm{c}}}
\end{array}\right.
$$

With Eqs. (5), (6), and (8) and defining $\theta$ as the ratio of TRR between the blade and the coating at the friction interface, then $\theta$ can be written as follows:

$$
\theta=\left.\frac{T_{\mathrm{b}}\left(x, t_{\mathrm{p}}\right)-T_{\mathrm{b} 0}}{T_{\mathrm{c}}\left(x, t_{\mathrm{p}}\right)-T_{\mathrm{c} 0}}\right|_{x \rightarrow 0}=\frac{\frac{2 \cdot q_{\mathrm{b}} \cdot \sqrt{\frac{a_{\mathrm{b}} \cdot t_{\mathrm{bp}}}{\pi}}}{\frac{K_{\mathrm{b}}}{2 \cdot q_{\mathrm{c}} \cdot \sqrt{\frac{a_{\mathrm{c}} \cdot t_{\mathrm{cp}}}{\pi}}}}=\sqrt{\frac{t_{\mathrm{bp}}}{t_{\mathrm{cp}}}} \cdot \sqrt{\frac{a_{\mathrm{b}}}{a_{\mathrm{c}}}}}{K_{\mathrm{c}}}
$$

From Eq. (9), it can be seen that the square root ratio of the thermal diffusivities of the blade and the coating could be used as $\theta$, an indicator of the ratio of TRR. The proportionality factor is the square root ratio of the rubbing time for the blade and the coating during one rubbing process. For the blade, the rubbing time $t_{\mathrm{bp}}$ can be calculated as

$$
t_{\mathrm{bp}}=\frac{L}{V_{\mathrm{t}}}
$$

For the coating, the rubbing time $t_{\mathrm{cp}}$ can be written as

$$
t_{\mathrm{cp}}=\frac{b}{V_{\mathrm{t}}}
$$

where $b$ is the blade thickness (Fig. 11). With Eqs. (9), (10), and (11), $\theta$ can be expressed as

$$
\theta=\sqrt{\frac{L}{b}} \cdot \sqrt{\frac{a_{\mathrm{b}}}{a_{\mathrm{c}}}}
$$

The blade thickness $b$ is a constant; here, it is equal to $4 \mathrm{~mm}$. The scratch length $L$ is a variable and related to the rubbing depth. The larger the rubbing depth, the greater the value of $L$. Because the total rubbing depth in this study was $0.4 \mathrm{~mm}$, it seems reasonable to choose the $L$ value when the rubbing depth reached $0.2 \mathrm{~mm}$ to represent the average scratch length. When the rubbing depth is $0.2 \mathrm{~mm}, L$ is $17.8 \mathrm{~mm}$. Therefore, Eq. (12) can be rewritten as

$$
\theta=\sqrt{\frac{L}{b}} \cdot \sqrt{\frac{a_{\mathrm{b}}}{a_{\mathrm{c}}}}=\sqrt{\frac{17.8}{4}} \cdot \sqrt{\frac{a_{\mathrm{b}}}{a_{\mathrm{c}}}}=2.1 \sqrt{\frac{a_{\mathrm{b}}}{a_{\mathrm{c}}}}
$$

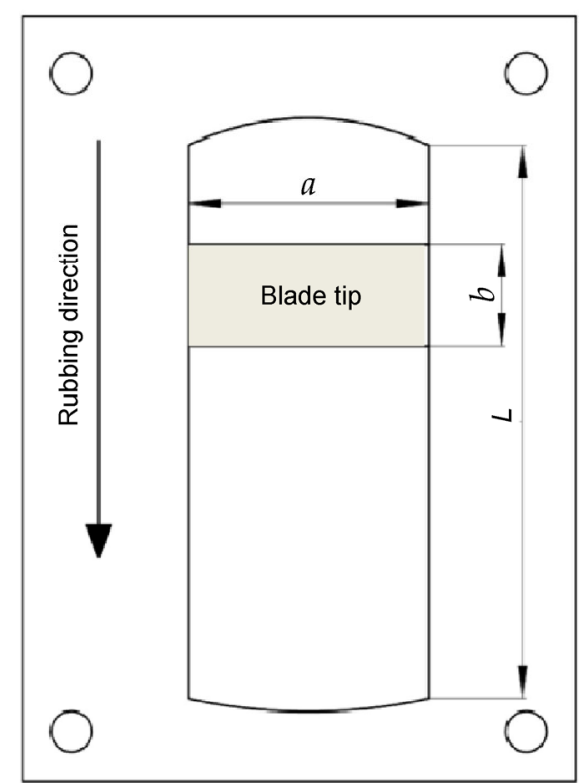

Fig. 11 Schematic diagram of blade width $a$, thickness $b$, and scratch length $L$. 


\subsection{Explanation of experimental phenomenon by the model}

Table 4 shows the relationship between blade wear status, damage mechanism, and $\theta$ of the three types of seal couples.

It is clear that the TRR for the blade in the Al-hBN couple was smaller than that of the coating, whereas in the Ni-Cg couple, the blade's TRR was bigger than that of the coating. The different TRR values in the two types of couples would lead to different mechanical vibrations for both the coating and the blade and therefore to different damage mechanisms.

For the Ni-Cg coating and $\mathrm{Ti}-6 \mathrm{Al}-4 \mathrm{~V}$ blade couple, according to $\theta=2.76$, when the temperature of the blade reached $550{ }^{\circ} \mathrm{C}$, the temperature of the coating was approximately $200{ }^{\circ} \mathrm{C}$. Ti-6Al-4V is not a temperature-resistance alloy; its UTS decreases to $498 \mathrm{MPa}$ at $550{ }^{\circ} \mathrm{C}$, which is approximately $51 \%$ of its UTS value at room temperature, as shown in Fig. 12 [26]. By contrast, nickel is a high-temperature alloy element, making the $\mathrm{Ni}-\mathrm{Cg}$ coating more temperatureresistant than the blade.

The high-temperature hardness test showed that the hardness of the Ni-Cg coating at $450{ }^{\circ} \mathrm{C}$ was $30-33$ HR15Y, which is approximately $60 \%-66 \%$ at room temperature. This means that the $\mathrm{Ni}-\mathrm{Cg}$ coating retained its mechanical strength better than the $\mathrm{Ti}-$ $6 \mathrm{Al}-4 \mathrm{~V}$ blade with temperatures at the friction interface of $200{ }^{\circ} \mathrm{C}$ for the coating and $550{ }^{\circ} \mathrm{C}$ for the blade.

The combined effect of a larger TRR and poor temperature-resistance properties caused the Ti-6Al-4V blade tip to soften earlier and more seriously than the $\mathrm{Ni}-\mathrm{Cg}$ coating. The blade therefore lost its mechanical advantage to the coating during the rubbing process.
Therefore, under high-speed rubbing, where the friction heat effect was strong, abrasive wear and plastic deformation appeared on the surface of the Ti-6Al-4V blade tip, which is a sign of severe softening.

In addition, the contacted asperities of the blade tip and coating surface may have been welded together under the strong action of friction heat. The welded spot may be more likely to shear off and break away from the blade tip, which was severely softened, and be left on the surface of the coating scar, forming the blade-coating mixed-layer blocks (Figs. 4. (c)-4(e)).

For the Al-hBN coating and Ti-6Al-4V blade couple, according to $\theta=0.93$, the coating has the bigger TRR. This situation results in two consequences as follows:

First, the temperature resistance of aluminum, which constitutes the metal phase and the source of strength for the coating, is very poor. For example, when the temperature reached $300{ }^{\circ} \mathrm{C}$, the UTS of $\mathrm{Al}$ was approximately half at room temperature. Meanwhile, according to $\theta=0.93$, the temperature of the blade at the interface was just $279{ }^{\circ} \mathrm{C}$. Also from Fig. 12, the UTS of Ti-6Al-4V was $702 \mathrm{MPa}$ at $279{ }^{\circ} \mathrm{C}$, which is approximately $73 \%$ of its UTS at room temperature (967 MPa). This means that when the Al-hBN coating is severely softened, the Ti-6Al-4V blade can still keep its strength.

Second, the Al-hBN coating is a low-melting-point coating (initial melting point just $636{ }^{\circ} \mathrm{C}$ ), which means it is very easy to become molten/semi-molten.

The softened or molten/semi-molten coating was very easy to shear off and adhere to the surface of the blade tip under the action of friction. Therefore, the blade had minimal damage and was significantly lengthened by the adhesive coating material.

Table 4 Relationship between blade wear status, damage mechanism and $\theta$ (the ratio of TRR).

\begin{tabular}{ccccccccc}
\hline $\begin{array}{c}\text { Seal coating } \\
\text { matching with } \\
\text { Ti-6Al-4V blade }\end{array}$ & $a_{\mathrm{b}}$ & $a_{\mathrm{c}}$ & $\theta=\sqrt{\frac{a_{\mathrm{b}}}{a_{\mathrm{c}}}}$ & $\begin{array}{c}\text { Spark } \\
\text { phenomenon }\end{array}$ & $\begin{array}{c}\text { Main damage mechanism } \\
\text { of the blade }\end{array}$ & $\begin{array}{c}\text { Blade length } \\
\text { loss (um) }\end{array}$ & $\begin{array}{c}\text { Blade length } \\
\text { change }\end{array}$ \\
\hline Ni-Cg & & 1.69 & 2.76 & Intense & $\begin{array}{c}\text { Severe abrasive wear and } \\
\text { blade transfer to the coating } \\
\text { Moderate abrasive wear and }\end{array}$ & $\begin{array}{c}\text { Seriously } \\
\text { shortened }\end{array}$ \\
AlSi-Polyester & 2.91 & 3.21 & 2.00 & Moderate & $\begin{array}{c}\text { Moderate } \\
\text { slightly coating adhesive to blade }\end{array}$ & Mongthen \\
Al-hBN & 14.7 & 0.93 & No & Severe coating adhesive to blade & -838 & $\begin{array}{c}\text { Seriously } \\
\text { lengthened }\end{array}$ \\
\hline
\end{tabular}

*Annotation: blade's thermal diffusivity was obtained from ref. [25]; coating's thermal diffusivity was obtained by experimental measured 


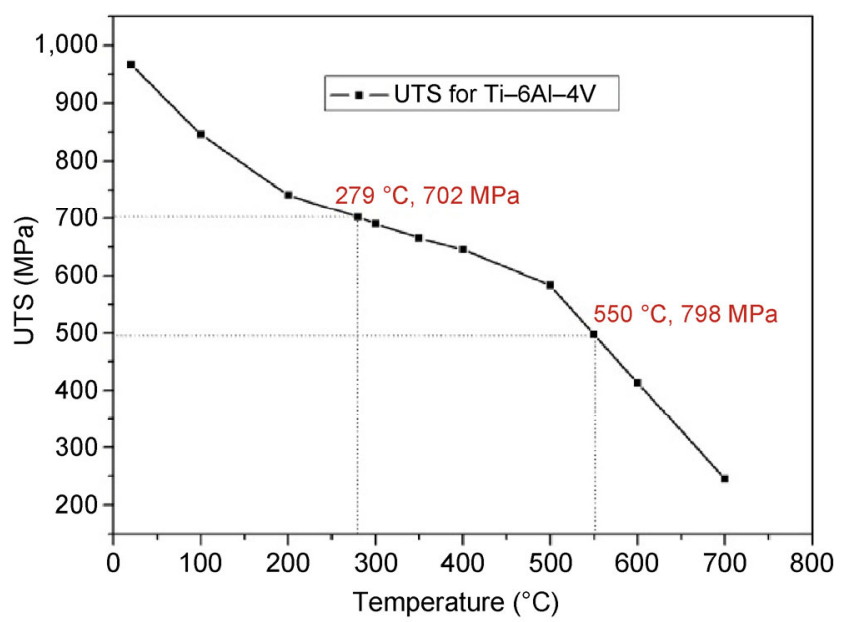

Fig. 12 The relationship between UTS and temperature of Ti-6Al-4V.

From the analysis described above, it is clear that the ratio of the blade's TRR and the coating's TRR, $\theta$, has a very strong influence on the wear status and damage mechanism of seal friction couples.

If $\theta>1$, it means the blade has the bigger TRR, and thus it tends to suffer more serious softening than the coating or it suffers softening first. Abrasive wear and plastic deformation or blade material transfer to the coating, and even more serious damage form would be suffered to the blade.

If $\theta<1$, it means blade has a TRR smaller than that of the coating. The blade therefore tends to retain its mechanical strength, whereas the coating softens. Thus, blade wear loss can be reduced or even be replaced by adhesion of the coating material to the blade.

In order to confirm the validity and applicability of the theory, another type of seal friction couple, an $\mathrm{AlSi}-$ polyester coating versus a $\mathrm{Ti}-6 \mathrm{Al}-4 \mathrm{~V}$ blade was tested and the results are shown in Table 4.

With $\theta$ gradually decreased from 2.76 in the $\mathrm{Ni}-\mathrm{Cg}$ couple to 2 in the AlSi-polyester couple, the spark phenomenon varied from intense to moderate. Slightly coating adhesion on the blade tip took the place of blade transfer to the coating, and the degree of abrasive wear decreased. In addition, the blade wear status changed from seriously shortened $(221 \mu \mathrm{m})$ to moderately lengthened $(-101 \mu \mathrm{m})$ as a result of coating adhesion.

With a further decrease of $\theta$ from 2 to 0.93 in the Al-hBN couple, the spark phenomenon absolutely disappeared. Coating adhesion to the blade became the main mechanism, and the blade was significantly lengthened $(-838 \mu \mathrm{m})$.

Thus, the theory seems well consistent with the experiment results.

It is important to note that when comparing the blade wear form and $\theta$, it seems there may be a critical value for $\theta$ at which the blade wear forms change from severe abrasive wear (in the $\mathrm{Ni}-\mathrm{Cg}$ couple) to a combination of moderate abrasive wear and coating adhesion (in the AlSi-polyester couple) to total coating adhesion (in the AlSi-hBN couple). However, the data are limited, and it would be premature to decide whether a critical value for $\theta$ really exists. Much more data is needed to determine the critical value.

It also must be pointed out that although the blade wear behaviors in the two seal couples used in this study can be well explained by the ratio of TRR, i.e., thermal conductivity, other coating material properties such as coating melting temperature also had a strong influence on the blade wear behavior. For example, if the coating melting temperature is high, the temperature at the interface must be also be relatively high when the coating softens. Obviously, this is not good for reducing blade wear.

The purpose of this study was mainly to elaborate the relationship between the ratio of TRR and the blade wear behavior. Therefore, the effect of coating melting temperature or other material properties was beyond the scope of this study; these issues will be discussed in subsequent research works.

\section{Conclusions}

The tribological behaviors of two types of seal friction couples were studied. In the $\mathrm{Ni}-\mathrm{Cg}$ and $\mathrm{Ti}-6 \mathrm{Al}-4 \mathrm{~V}$ couple, the blade tip exhibited serious wear, and the damage mechanisms were plastic deformation and blade material transfer to the coating. In the Al-hBN and $\mathrm{Ti}-6 \mathrm{Al}-4 \mathrm{~V}$ couple, the wear of the blade was minimal; in some cases, the blade was even lengthened, which was mainly caused by coating adhesion.

Linear velocity is a very important parameter that influences the wear behavior of seal couples. Under high linear velocities, blade wear or blade lengthening was markedly enhanced as compared to low linear velocity. 
The temperature rising rate (TRR) of the friction couple at the interface has a crucial influence on the blade wear status and damage mechanism. In the $\mathrm{Ni}-\mathrm{Cg}$ and Ti-6Al-4V seal couple, the TRR of the $\mathrm{Ti}-6 \mathrm{Al}-4 \mathrm{~V}$ blade was faster than that of the $\mathrm{Ni}-\mathrm{Cg}$ coating, so the Ti- $6 \mathrm{~A}-4 \mathrm{~V}$ blade softened earlier than the $\mathrm{Ni}-\mathrm{Cg}$ coating, and the blade suffered severe wear. In the Al-hBN and Ti-6Al-4V seal couple, the TRR of the Ti- $6 \mathrm{Al}-4 \mathrm{~V}$ blade is slower than that of the Al-hBN coating, and so the Al-hBN coating softened first and blade damage was reduced or even replaced by coating adhesion.

The square root ratio of the thermal diffusivities of the blade and coating can be taken as a good indicator of the blade TRR and coating TRR, making it possible to predict blade wear status to a certain extent. The experimental results of the two seal couples used in this study agreed well with the theoretical results.

\section{Acknowledgements}

This project was supported by State Key Laboratory of Tribology, Tsinghua University (No. SKLTKF12B15).

Open Access: The articles published in this journal are distributed under the terms of the Creative Commons Attribution 4.0 International License (http:// creativecommons.org/licenses/by/4.0/), which permits unrestricted use, distribution, and reproduction in any medium, provided you give appropriate credit to the original author(s) and the source, provide a link to the Creative Commons license, and indicate if changes were made.

\section{References}

[1] Bill R C, Ludwig L P. Wear of seal materials used in aircraft propulsion systems. Wear 59: 165-189 (1980)

[2] Hajmrle K, Fiala P, Chilkowich A P. Abradable seals for gas turbines and other rotary equipment. In Proceedings of ASME Turbo Expo 2004, 2004: 14-17

[3] Chupp R E, Hendricks R C, Steinetz B M. Sealing in turbomachinery. Journal of Propulsion and Power 22(2): 313-349 (2006)

[4] Ludwig L P, Bill R C. Gas Path Sealing in Turbine Engines. Tribol Trans 23(1): 1-22 (1980)

[5] Bounazef M, Guessasma S, Ait Saadi B, Aourage H. Seal creation of abradable material NiCrAl-boron nitride-polyester. In Proceedings of the Third International Conference on Advances in Mechanical Engineering and Mechanics, Hammamet, Tunisie, 2006: 17-19

[6] Emery A F, Wolak J, Etemad S. An experimental investigation of temperatures due to rubbing at the blade-seal interface in an aircraft compressor. Wear 91(2): 117-130 (1980)

[7] Wolak J, Emery A F, Etemad S. Preliminary results on the abradability of porous, sintered seal material. Journal of Lubrication Technology (Transactions of the ASME) 105: 576-582 (1983)

[8] Bill R C, Shiembob L T. Friction and wear of sintered fibermetal abradable seal materials. In Intern. Conf. on Wear of Materials, St. Louis, MO United States, 1977: 421-427.

[9] Irissou E, Dadouche A, Lima RS. Tribological Characterization of plasma-sprayed CoNiCrAlY-BN abradable coatings. Journal of Thermal Spray Technology 23(1-2): 252-261 (2014)

[10] Taylor T A, Thompson B W, Aton W. High speed rub wear mechanism in IN-718 vs. NiCrAl-Bentonite. Surf Coat Technol 202(4-7): 698-703 (2007)

[11] Borel M O, Schmid R K, Nicoll A R. Improved abradable coatings using wear mechanism mapping and Microstructural modeling. In Proceedings of the 3rd National Thermal Spray Conference, California, Amearica, 1990: 119-123.

[12] Borel M O, Nicoll A R, Schmid R K. The wear mechanisms occurring in abradable seals of gas turbines. Surf Coat Technol 39-40(Part 1): 117-126 (1989)

[13] Wang H G. An analysis of turbine blade/abradable seal rubbing. In Proceedings of the 1st International Conference on Processing Materials for Properties, Hawaii, America, 1993: 1085-1088

[14] Wang H G. Criteria for analysis of abradable coatings. Surf Coat Technol 79(1-3): 71-75 (1996)

[15] Bounazef M, Guessasma S, Ait Saadi B. The wear, deterioration and transformation phenomena of abradable coating BN-SiAl-bounding organic element, caused by the friction between the blades and the turbine casing. Mater Lett 58(27-28): 3375-3380 (2004)

[16] Ghasripoor F, Schmid R K, Dorfman M F, Russo L. A review of clearance control wear mechanism for low temperature aluminium silicon alloys. In Proceedings of the 15th International Thermal Spray Conference, Nice, France, 1998: 25-29.

[17] Fois N, Watson M, Stringer J, Marshall M B. An investigation of the relationship between wear and contact force for abradable materials. In Proceedings of the Institution of Mechanical Engineers, Part J, Journal of Engineering Tribology Online Published, 2014: 1-15 
[18] Fois N, Stringer J, Marshall M B. Adhesive transfer in aero-engine abradable linings contact. Wear 304(1-2): 202-210 (2013)

[19] Stringer J, Marshall M B. High speed wear testing of an abradable coating. Wear 294-295: 257-263 (2012)

[20] Laverty W F. Rub energetics of compressor blade tip seals. Wear 75: 1-20 (1982)

[21] Kennedy F E. Thermomechanical phenomena in high speed rubbing. Wear 59(1): 149-163 (1980)

[22] Gao S Y, Liu S W, Li S, liu Y. Evaluation of wear resistance of abradable coating by a single-pass pendulum scratch method. Tribology 30(4): 385-391 (2010)

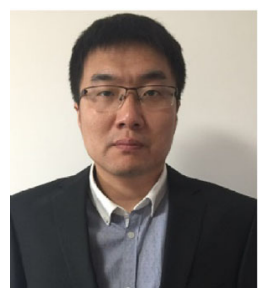

Siyang GAO. He received his bachelor and master degrees in materials processing engineering from Shenyang University of Technology, Shenyang, China, in 2005 and 2008 respectively. He obtained his Ph.D. degree in

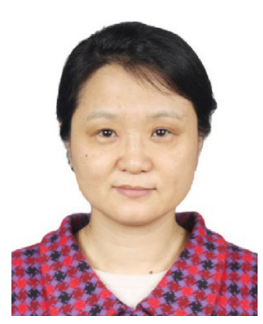

Deli DUAN. She received her B.S. in chemistry from Jilin University in 1991 and Ph.D degree in material science from Institute of Metal Research, CAS in 2006 . Her current position is a pro-

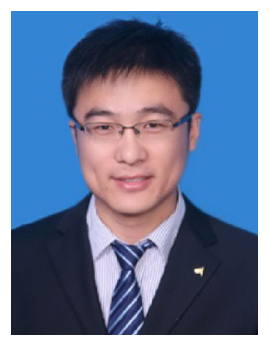

Weihai XUE. He received his Ph.D degree in materials science in 2015 from Institute of Metal Research, Chinese Academy of Sciences (IMR), Shenyang, China. His current

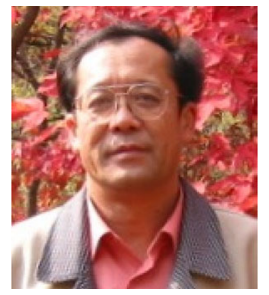

Shu LI. He received his M.S. and Ph.D degrees in materials science from Institute of Metal research, Chinese Academy of Sciences, Shenyang, China, in 1990 and 2001 respectively. He joined the Institute
[23] Johnston R E. Mechanical characterisation of AlSi-hBN, NiCrAl-Bentonite, and NiCrAl-Bentonite-hBN freestanding abradable coatings. Surf Coat Technol 205(10): 3268-3273 (2011)

[24] Johnston R E, Evans W J. Freestanding abradable coatingmanufacture and tensile test development. Surf Coat Technol 202(4-7): 725-729 (2007)

[25] Zhang H J. Heat Conduction. Beijing (China): Higher Education Press, 1982

[26] Yan M G. Handbook on China Aeronautical Materials, Volume 4. Standars Press of China, 2001

materials science in 2012 from Institute of Metal research, Chinese Academy of Sciences, Shenyang, China. His research interests include materials tribological behaviors under special conditions.

fessor of Institute of Metal Research, CAS. Her research areas cover the tribology of materials under special environment and electro-thermal materials and devices.

position is a research assistant in IMR. His research interests include high-speed rubbing tribology and tribo-corrosion of biomaterials.

of Metal research from 1991. His current position is a senior research fellow. His research areas cover the materials tribological behaviors under special conditions and tribological evaluation method for engineering materials. 